\title{
Gambaran Penyesuaian diri Lansia dalam Konteks Model Adaptasi Roy di Loka Rehabilitasi Sosial Lanjut Usia Kendari
}

\author{
Anggi Nurza'da Pebrianti $\mathbf{M}^{\mathbf{1}}$, Diah Indriastuti ${ }^{\mathbf{1}^{*}}$, Mien ${ }^{\mathbf{1}}$ \\ ${ }^{1}$ Sekolah Tinggi Ilmu Kesehatan Karya Kesehatan, Kendari, Indonesia \\ nsdiahindri@gmail.com
}

\begin{abstract}
Introduction: Changes in the elderly need social support from friends, family and the surrounding environment so that they can easily adjust to the changes that occur. This study aimed to describe the self-adjustment of the elderly in the context of Roy's Adaptation Model at the Elderly Social Rehabilitation (ESR) of Kendari.

Methods: The study was a qualitative research with a phenomenology approach. The participants in this study were eight elderly who lived in Kendari's ESR and two nurses as triangualition participants. Sampling used a purposive sampling technique. The researchers employing in-depth interview, observation, dan documentation study in collecting data. The data were analyzed using thematic analysis.

Results: The study resulted in four themes including entry process to ESR, self-change, coping mechanisms and response indicate that the elderly self-adjusment social rehabilitationsite in the context of Roy's Adaptation Model describing the human adaptation system through several stages, namely input, control and output where in the life of the elderly who live in ESR is influenced by the entry process in LRSLU as an internal stimulus or an external stimulus. Thus, there is a process of selfadjustment in the form of self-change and coping mechanisms, with various kinds of coping carried out to produce a behavior in the form of adaptive or maladaptive responses.

Conclusion: This study concludes that the elderly in adjusting themselves through several stages namely input, control and output to adapt to the environment goodbye in the elderly social rehabilitation workshop (ESR) Kendari with self-changes and various coping mechanisms so as to produce behavioral responses.
\end{abstract}

Keywords: Elderly, Nursing Home, Roy's Adaptation Model, Self-Adjustment.

\begin{abstract}
Abstrak
Pendahuluan: Proses penuaan menyebabkan lansia sulit untuk melakukan Activity Daily Life (ADL) secara mandiri, merasa sendirian, frustasi, depresi dan kehilangan kepercayaan diri mereka sehingga banyak lansia yang sulit beradaptasi. Perubahan dalam diri lansia membutuhkan dukungan sosial dari teman, keluarga dan lingkungan sekitar agar dapat dengan mudah menyesuaikan diri dengan perubahan yang terjadi. Kurangnya kemampuan dalam beradaptasi secara psikologisterhadap perubahan yang terjadi pada dirinya, mengakibatkan sering kali terjadi permasalahan psikososial pada lansia. Penelitian ini bertujuan untuk mengetahui gambaran penyesuaian diri lansia dalam konteks Model Adaptasi Roy di Loka Rehabilitasi Sosial Lanjut Usia (LRSLU) Kendari.

Metode: Penelitian ini adalah penelitian deskriptif kualitatif. Partisipan dalam penelitian ini adalah delapan lansia yang tinggal di LRSLU Kendari. Pengambilan sampel menggunakan teknik purposive sampling. Metode pengambilan data menggunakan wawancara mendalam, observasi dan studi
\end{abstract}


dokumentasi. Triangulasi sumber dilaksanakan pada dua orang partisipan perawat. Data dianalisis menggunakan analisis tematik.

Hasil: Hasil penelitian ini dengan 4 tema yaitu proses masuk LRSLU, perubahan diri, mekanisme koping dan respon. Hal ini menunjukkan bahwa penyesuaian diri lansia di Loka Rehabilitasi Sosial Lanjut Usia (LRSLU) Kendari dalam konteks Model Adaptasi Roy menggambarkan sistem adaptasi manusia melalui beberapa tahap yaitu input, kontrol, dan output dimana dalam kehidupan lansia yang tinggal di LRSLU dipengaruhi oleh proses masuk di LRSLU sebagai stimulus internal maupun stimulus eksternal sehingga terjadi proses refleksi perilaku individu terhadap proses penyesuaian diri berupa perubahan diri dan mekanisme koping, dengan berbagai macam koping yang dilakukan untuk menghasilkan suatu perilaku berupa respon yang adaptif maupun maladaptif.

Kesimpulan: Simpulan penelitian ini adalah lansia dalam penyesuaian dirinya melalui beberapa tahap yaitu input, kontrol, dan output untuk beradaptasi terhadap lingkungan selama tinggal di LRSLU Kendari dengan perubahan diri dan mekanisme koping yang bervariasi sehingga menghasilkan respon perilaku.

Kata kunci: Lansia, Model Adaptasi Roy, Panti Wredha, Penyesuaian Diri.

\section{PENDAHULUAN}

Proses penuaan menyebabkan lansia sulit untuk melakukan Activity Daily Life $(A D L)$ secara mandiri, merasa sendirian, frustasi, depresi dan kehilangan kepercayaan diri sehingga banyak lansia yang sulit beradaptasi (Prabasari, Juwita, \& Maryuti, 2017). Depresi yang dialami lansia menyebabkan kesulitan untuk beradaptasi, sehingga membutuhkan suatu metode penyesuaian diri yang menjadikan sesseorang memiliki kemampuan menerima hal-hal di mana seseorang tidak mempunyai kontrol akan keadaan suatu perubahan (Prabasari et al, 2017).

Kejadian depresi pada lansia di dunia sekitar 8-15\% (Nauli, Yuliatri, \& Savita, 2014). Lansia di Indonesia sekitar 74\% memiliki potensi menderita masalah depresi akibat mengkonsumsi obat terus-menerus selama hidupnya (Nauli et al., 2014). Data hasil Riset Kesehatan Dasar mengenai prevalensi depresi penduduk Provinsi Sulawesi Tenggara tahun 2018 sebanyak 6,2\% (Kementerian Kesehatan Republik Indonesia, 2018). Data mengenai gangguan emosional terutama stress, prevalensi penduduk Sulawesi Tenggara yang mengalami gangguan mental atau stress sebesar 4,1\% (Afiah, Yusran, \& Sety, 2018).

Perubahan lingkungan merupakan salah satu faktor yang mempengaruhi seseorang karena harus menyesuaikan diri dengan lingkungannya, yang menyediakan sumber dukungan sosial positif agar lansia merasa bahagia, dan terhindar dari stress dan depresi (Indriana, Desiningrum, \& Kristiana, 2011; Jamil, 2012).

Penyesuaian diri yang baik dapat diukur dari cara mengatasi setiap perubahan yang terjadi dalam hidupnya (Isnawati \& Suhariadi, 2012). Kurangnya kemampuan dalam beradaptasi secara psikologis terhadap perubahan yang terjadi pada dirinya, mengakibatkan seringkali terjadi permasalahan psikososial pada lansia (Parasari \& Lestari, 2015).

Model konseptual keperawatan Adaptasi Sister Calista Roy menjelaskan individu sebagai sistem adaptif yang berinteraksi dengan lingkungan sebagai stimulus dan dapat berpengaruh pada kesehatannya (Adinugraha, 2014; Hadidi, 2015; Herawati, 2015). Model adaptasi ini dapat menjadi tolak ukur pada individu 
yang memiliki masalah atau kesulitan dalam beradaptasi terutama pada lansia yang umumnya berpotensi menderita depresi.

Studi pendahuluan yang dilakukan kepada salah satu pekerja sosial di Loka Rehabilitasi Sosial Lanjut Usia (LRSLU) melalui wawancara oleh peneliti kepada petugas mengatakan bahwa akibat dari perubahan fungsi dari panti wredha menjadi loka rehabilitasi adalah banyak lansia yang sudah lama tinggal terpaksa harus dipulangkan ke kampung halamannya. Saat ini lansia yang berada di LRSLU tinggal sebanyak 50 orang. Mayoritas lansia lebih nyaman tinggal di LRSLU dibanding di kampung halamannya, sehingga banyak lansia yang cemas dan khawatir dipulangkan.

Penelitian sebelumnya di salah satu rumah sakit di Jakarta menunjukkan bahwa penerapan Model Adaptasi Roy memberi kerangka berpikir perawat dalam pemberian asuhan keperawatan khusunya pada pasien diabetes mellitus, dimana perjalanan penyakit tersebut berpengaruh terhadap semua model holistik yang mempengaruhi pasien (Adinugraha, 2014). Penelitian lain menunjukkan bahwa setelah menerapkan Model Adaptasi Roy koping lansia dengan hipertensi meningkat menjadi koping efektif dari mean pre-test 78,60 menjadi nilai post-test 108,40 (Hadidi, 2015). Penerapan Model Adaptasi Roy dalam asuhan keperawatan pada gangguan endokrin, khususnya diabetes mellitus bertujuan agar pasien dapat beradaptasi, adanya proses adaptasi pada pasien gangguan endokrin dengan dibuktikan masalah teratasi atau sebagian teratasi (Purwanti, 2014).

Penyesuaian diri lansia pada LRSLU berbeda dengan hasil penelitian sebelumnya karena perbedaan masalah yang dihadapinya dan tempat atau lokasi tempat penelitian. Permasalahan yang dihadapi tersebut adalah lansia yang mengalami kasus kekerasan, mengalami perlakuan salah, berhadapan dengan hukum dan lansia menderita penyakit kronis dengan batas waktu tinggal maksimal 6 bulan, tergantung dengan kasus yang dialami (Crespo, 2019). Lansia rentan terhadap depresi dengan adanya permasalahan yang menyertai saat dirawat di LRSLU. Penelitian ini bertujuan untuk mengetahui gambaran penyesuaian diri lansia dalam konteks Model Adaptasi Roy di Loka Rehabilitasi Sosial Lanjut Usia Kendari.

\section{METODE}

Penelitian kualitiatif dengan pendekatan deskriptif kualitatif digunakan dalam penelitian ini. Penelitian ini dilaksanakan pada bulan Juli 2019. Ethical clearance diperoleh dari KEPK IAKMI PENGDA SULTRA dengan nomor 006/KEPK-IAKMI/VI/2019. Jumlah responden dalam penelitian ini sebanyak delapan orang dengan menggunakan teknik purposive sampling untuk pengambilan sampel. Metode pengambilan data menggunakan wawancara mendalam, observasi dan studi dokumentas. Data dianalisis menggunakan analisis tematik.

Validitas data dilaksanakan dengan membina hubungan saling percaya yang telah terbangun akibat lamanya interaksi bersama partisipan, menyusun audit track, menyusun thick description yang didapatkan selama penelitian, dan melakukan triangulasi sumber pada dua orang perawat yang bertugas merawat lansia partisipan. Trustyworthiness dilaksanakan dengan proses credibility, dependability, confirmability dan transferability. 
HASIL

Karakteristik Partisipan

Tabel 1. Karakteristik Partisipan

\begin{tabular}{|c|c|c|}
\hline \multicolumn{3}{|c|}{ Partisipan Lansia } \\
\hline \multirow{3}{*}{$\begin{array}{l}\text { Usia } \\
\text { (th) }\end{array}$} & Dewasa awal (20-30) & 2 \\
\hline & Elderly $(60-75)$ & 5 \\
\hline & Old $(75-90)$ & 3 \\
\hline \multicolumn{2}{|c|}{ Total } & 10 \\
\hline \multirow[t]{2}{*}{ Jenis Kelamin } & $\mathrm{P}$ & 5 \\
\hline & $\mathrm{L}$ & 5 \\
\hline \multicolumn{2}{|c|}{ Total } & 10 \\
\hline \multirow{2}{*}{$\begin{array}{l}\text { Status Di } \\
\text { LRSLU }\end{array}$} & \multirow{2}{*}{$\begin{array}{r}\text { Perawat } \\
\text { Lansia }\end{array}$} & 2 \\
\hline & & 8 \\
\hline \multicolumn{2}{|c|}{ Total } & 10 \\
\hline \multirow{2}{*}{$\begin{array}{c}\text { Lama Tinggal } \\
\text { Lansia }\end{array}$} & $<5$ th & 4 \\
\hline & $>5$ th & 4 \\
\hline \multirow[t]{2}{*}{$\begin{array}{c}\text { Masa Kerja } \\
\text { Perawat } \\
\end{array}$} & $<5$ th & 2 \\
\hline & Total & 10 \\
\hline \multirow{3}{*}{$\begin{array}{c}\text { Status } \\
\text { perkawinan }\end{array}$} & Menikah & 2 \\
\hline & Belum Menikah & 4 \\
\hline & Janda/duda & 4 \\
\hline \multicolumn{2}{|c|}{ Total } & 10 \\
\hline \multirow{3}{*}{$\begin{array}{c}\text { Pendidikan } \\
\text { Terakhir }\end{array}$} & Tidak lulus SD & 4 \\
\hline & SD & 4 \\
\hline & DIII Keperawatan & 2 \\
\hline & tal & 10 \\
\hline
\end{tabular}

Pelaksanaan penelitian bersama 10 orang partisipan tidak mengalami kendala dalam pertemuan antara peneliti dan partisipan karena partisipan tinggal bersama di dalam Loka Rehabilitasi Sosial Lanjut Usia (LRSLU) Kendari. Partisipan dalam penelitian ini paling banyak berstatus duda sebanyak 3 orang. Umur partisipan yang tertua adalah 90 tahun. Jenis kelamin lakilaki dan perempuan masing-masing 5 orang. Lama tinggal di LRSLU partisipan bervariasi, paling lama 24 tahun dan paling baru 7 bulan. Partisipan perawat dalam penelitian ini sebanyak 2 orang dengan pendidikan DIII Keperawatan, dan lama kerja masing-masing adalah 1 tahun dan 2 tahun.

\section{Gambaran aplikasi model adaptasi Roy dilihat dari tahap input di LRSLU Kendari}

Gambaran Input lansia LRSLU terbagi dalam 1 tema, yakni proses masuk. Tema proses masuk LRSLU digambarkan melalui 2 kategori yaitu penyebab masuk ke LRSLU dan pengantar ke LRSLU.

\section{Tema proses masuk}

Kategori 'penyebab masuk di LRSLU' menunjukkan stimulus fokal yang dialami oleh lansia. Lansia mengalami kondisi tidak memiliki kemampuan untuk mengusahakan nafkah secara mandiri menjadi penyebab tinggal di panti sosial (bentuk administratif awal dari LRSLU) dan ketika berubah menjadi LRSLU partisipan tidak dapat dikembalikan pada keluarganya karena keluarga tidak memiliki kemampuan untuk merawat lansia. Hal ini dibenarkan oleh partisipan triangulasi yang dijumpai dalam pernyataan partisipan sebagai berikut:

"Yah bagaimana sudah nda bisa kerja..." (P1)

"Saya sudah sakit jadi nda bisa bekerja lagi” (P7)

"Ma itumi kalau sudah tidak punya apaapa...” (P4)

"Namanya saya sudah sengsara mi, sudah tidak punya apa-apa” (P6)

"Beragam yah...sudah tidak punya apa-apa jadi keluarga tidak mampu merawat ..." (PT2)

Beberapa partisipan tinggal di panti (sebelum berubah menjadi LRSLU) karena sudah tidak memiliki keluarga dan partisipan lainnya menyatakan alasanya 
untuk tinggal di panti karena ketidakharmonisan dengan keluarga yang tinggal dalam satu rumah. Partisipan yang tidak memiliki keluarga tetap tinggal di LRSLU dikarenakan tidak terlacak data penanggung jawab lansia. Partisipan triangulasi menyatakan bahwa lansia yang tidak harmonis dengan keluarga menurut kebijakan baru akan dikembalikan kepada keluarga setelah maksimal 6 bulan perawatan dengan diberikan pembekalan serta bimbingan pada keluarga dan lansia.

“...karna saya sudah nda punya keluarga" (P8)

“...sudah nda punya keluarga...” (P2)

“..nda akur sama ipar jadi dibawa sama adek kesini..” (P5)

"Penyebabnya beda-beda ada yang karena tidak akur dengan keluarganya, ada juga yang terlantar ditempat umum karena tidak ada keluarganya........." (PT1)

"Beragam yah, biasanya karena terlantar karena sudah tidak punya keluarga...tapi sekaranag karena perubahan kebijakan..." (PT2)

Kategori 'pengantar ke LRSLU' merupakan stimulus residual yang berasal dari eksternal individu. Partisipan memiliki kondisi dan pengalaman yang tidak mendukung fase lansianya sehingga hanya 1 orang saja dari partisipan yang proses datang ke LRSLU diantar oleh pihak keluarga, selebihnya dijemput langsung oleh pihak panti(sebelum berubah nama). Kondisi ini dapat dijumpai dalam pernyataan partisipan sebagai berikut:

"Memohon sendiri di kantor lasusua langsung dijemput pegawai sini..." (P1)
“Saya dijemput pihak panti..." (P2)

“.... dijemput pegawai naek mobil” (P3)

“...dowonggu memohon, inakupo lako nipamarenda melaporo, ihiropo petuha umaleaku i kua....( memohon sendiri, saya yang lapor ke pemerintah, mereka yang turun ambil saya)" (P4)

“.... dibawa adik saya datang ke sini...." (P5)

“....saya diantar pemerintah dari kota lama.” (P6)

“....saya memohon sendiri, kirim surat ke sini.” (P7)

"Saya datang memohon sendiri ke sini...." (P8)

Proses ini terkonfirmasi oleh petugas dari LRSLU yang menjelaskan bahwa ada pemeriksaan terlebih dahulu sebelum dijemput untuk tinggal di LRSLU, berikut adalah pernyataan dari petugas:

"iya benar, tapi ada prosesnya harus mengkaji dulu mengenai kondisi lansia tersebut apakah layak masuk ke Loka, kalau layak baru kami jemput...." (PT1)

"itu benar adanya, karena beberapa lansia yang masuk itu karena pemerintah setempat melapor sehingga kami menjemput ke lokasi lansia berada atau diantar pemerintah.... (PT2).

\section{Gambaran aplikasi model adaptasi Roy dilihat dari tahap control di LRSLU Kendari}

Gambaran control lansia LRSLU terbagi dalam 2 tema, yakni kesehatan lansia dan 
mekanisme koping. Untuk lebih jelasnya di uraikan sebagai berikut:

\section{Kesehatan Lansia}

Kategori yaitu gangguan kesehatan. Kategori gangguan kesehatan menunjukkan bahwa partisipan 7 mengalami sistem adaptasi pada tahap mekanisme regulator karena kondisi sakitnya yang mulai berangsur pulih ketika dirawat di panti dibandingkan ketika di rawat di tempat asalnya (sebelum ke panti) tanpa keluarga. Partisipan lainnya cenderung mengalami tahap mekanisme kognator karena kondisi tubuhnya tidak mengalami gangguan kesehatan yang berarti serta telah mempunyai jadwal rutin untuk perawatan baik di poli LRSLU ataupun di RS rujukan. Lansia hanya cenderung mengalami kekurangan dukungan dan lingkungan yang baik untuk hidup dalam usianya. Secara anatomis dan fisiologis dapat beradaptasi dengan baik dengan melakukan perawatan mandiri yang sudah diketahuinya. Pernyataan partisipan berikut menjelaskan mengenai sistem mekanisme regulator:

“... saya juga punya sakit jantung suka kontrol di RS abunawas.” (PI)

"Nda ada keluhan apa-apa, selama ini sehat-sehat alhamdulillah." (P2)

"Nda ada keluhan sakit, cuma ini nda bisa liat dari lahir ..." (P3)

“...dasarnya suka sakit punggung yah pasrah mau diapa, karena mau gimana lagi namanaya sudah tua." (P4)

"Saya sakit pinggang saya kasih pake balsem biar mendingan. Kadang kalau sakit sekali suka minta diurut." (P5)
"Ini rematik, lututku saya suka oles-oles pake air hangat. Kalau sudah begitu pasti enak kembali saya rasa sakitnya berkurang." (P6)

"Saya sudah sakit...sakit dua lutut saya ini, pakai minyak gosok jadi mendingan...sejak di panti jadi lebih baik..." (P7)

"Kalo rematik saya kompres dengan air hangat dan kompres jahe yang diajarkan mahasiswa. Efeknya terasa skali sakitsakitnya langsung hilang." (P8)

"Biasanya lansia datang ke poli, atau biasa juga saat kami keliling wisma mengecek keadaan mereka ngeluh tentang sakitnya." (PT1)

"Lansia datang ke poli dan kadang juga ngeluh langsung sama pegawai. Tapi mereka juga ada beberapa yang udah bisa pakai obat herbal buat sendiri untuk meredakan nyeri yang dirasakan." (PT2)

\section{Mekanisme Koping}

Tema mekanisme koping merupakan sistem adaptasi pada tahap mekanisme kognator. Lansia mengalami pengalaman yang melibatkan emosi, persepsi dan penilaiannya selama tinggal di panti (LRSLU) dimana sebelumnya kehilangan dukungan dari keluarga sebagai pendukung utama. Lansia mendapatkan dukungan baru dari teman sebayanya di panti sebagai ganti hilangnya dukungan keluarga.

Tema ini digambarkan melalui tiga kategori yaitu yang ketegori merindukan keluarga, hubungan dengan teman lansia, dan perasaan berada LRSLU. Walaupun lansia mengalami pengalaman menyedihkan mengenai keluarga sebelum akhirnya memutuskan untuk membuat permohonan perawatan di panti, keluarga tetap menjadi bagian penting dalam 
hidupnya yang tidak bisa dilupakan. Selama menjalani kehidupan di panti, lansia berusaha untuk menerima keadaan jauh ataupun tidak lagi dikenal oleh keluarga karena terputus komunikasi sejak lama. Kategori merindukan keluarga melibatkan banyak emosi lansia yang tergambar dalam pernyataan partisipan berikut ini:

"Yah nda ada lagi... kan suami tinggal disini juga jadi tidak ada hal-hal khusus." (P1)

“...nda ada, kecuali kalau keluarga di jawa nda tau tidak bisa dihubungi...” (P2)

"Yah ingat yang dulu saja waktu ke kebon bareng keluarga bantu mama jualan sayuran. Hanya bisa ingat-ingat saja." (P3)

"Akhir-akhir ini sering ingat kampung, ma rencana nggo mbule malapa leesu (rencana mau pulang lebara dulu ini).” (P4)

"Ingat kampung di Jawa, kampong halaman di sana tempat lahir nda mungkin saya lupakan." (P5)

"Pasrah saja baru saya sholat, kasih doa bae-bae untuk keluarga kalau ingat mereka..." (P6)

"Tidak ada, tidak ingat siapa-siapa saya.. saya pasrah saja..." (P7)

"Sedih sekali pas berpisah dengan istri saya tapi mau di apa mungkin sudah nasib saya gini, yah diam saja...pasrah saja, apalagi ini sudah berpisah sama istri..." (P8)

"Biasanya kalau yang punya handphone keluarganya ditelpon, kadang mereka cuma mau tanya kabar tapi ada juga yang mau minta izin datang berkunjung”(PT1)

"Kalau keluarganya masih bisa dihubungi kadang ditelpon." (PT2)

Kategori hubungan dengan teman lansia di LRSLU menunjukkan bagaimana partisipan dapat mencoba mengendalikan rasa kehilangan keluarga dengan saling berinteraksi dengan teman senasib. Pernyataan tersebut melibatkan persepsi lansia mengenai kondisi saat ini bersama dengan penghuni panti lainnya yang tergambar sebagai berikut:

"Yah cerita-cerita, menceritakan hal yang masih diingat dulu." (PI)

"Sangat baik, kadang saya suka ke wisma lain kalau diajak makan atau masak yang dikasih sama keluarganya” (P2)

"Hubungannya tentunya yah baik disini, bisa bersama lansia yang lain.” (P3)

"Di sini dia bagus masing-masing dia orang, bukan seperti di desa gila urusan..." (P4)

"Bagus semua, bisa sama-sama sampai tua di sini." (P5)

"Begitu saja nonton, karena sudah tua sama-sama sudah tidak kuat." (P7)

"Baik sering cerita saja sama yang lain, apalagi kalau udah akrab cerita lamalama." (P8)

“Bagus juga, tapi kadang juga ada cekcok sedikit, yah namanya lansia sudah umur labil kembali. Tapi banyak juga yang ketika cekcok tapi baikan sendiri."(PT1) 
"Cukup bagus yah, meski ada terkadang permasalahan antar lansia. Walaupun kadang juga masalah sepele tapi itu namanya emosinya sudah seperti anakanak kembali, sensitif lah..."(PT2)

Kategori perasaan tinggal di LRSLU merupakan cara lansia menilai kehidupannya di panti. Hal ini dapat dilihat dari pernyataan partispan berikut:

"Senang, pegawainya baik, jadi kalau pegawainya baik kita juga pasti senang." (P1)

"Pas pertama kali masuk suasana di sini itu tenang, nda berisik." (P2)

"Iki pas aku datang pertama kali masuk d isini yo senang lah, semua hal di sini bikin senang." (P3)

"Ma meambo iyepokaa (yah bagus jugaa memang), kita sudah tinggal di sini semuanya sudah disiapkan bersyukur..." (P4)

"Bagus, semua serba ada. Tinggal dari kita saja banyak-banyak bersyukur.” (P5)

"Tentu bagus, namanya orang sengsara dibawa ke sini, hidup di sini makanan semua sampai tempat tidur disediakan." (P6)

"Suka disini, hal-hal yang terjadi selama hidup dijadikan pelajaran, sekarang menikmati masa tua di sini." (P7)

"Tenang di sini, pegawai baik semua, fasilitas dikasih.” (P8)

"Lansia responnya awalnya bingung sama kondisi di sini, tapi akhirnya suka juga. Memang butuh waktu untuk mereka beradaptasi terhadap lingkungan disini, tapi karena kami berusaha membiasakan mereka Alhamdulillah semua lancar." (PT1)

"Meski awal-awal masih susah beradaptasi, masih murung tapi makin kesini udah senang, apalagi kalau sudah dapat teman lansia yang cocok diajak ngobrol, pasti betah dan nda bosan mereka itu." (PT2)

\section{Gambaran aplikasi Model Adaptasi Roy dilihat dari tahap output di LRSLU Kendari}

Gambaran output lansia LRSLU terbagi dalam satu tema, yakni respon. Tema respon digambarkan melalui kategori respon adaptif. Kategori respon adaptif adalah hasil akhir dari proses adaptasi yang dialami oleh lansia dan menghasilkan respon baik yang dapat mendukung kegiatannya setiap hari. Respon tersebut dapat dilihat pada pernyataan berikut:

"Namanya hidup pasti ada kalanya kita dapat masalah, yah biasa saja kalo saya itu nda pernah marah.” (Pl)

"Yah perasaan sedihnya kadang hilang juga yah. Sudah terbiasa kendalikan emosi. Karena di sini harus kita jaga bukan cuma rumah sendirita." (P2)

"Nda pernah bosen, senang semuanya saya sukalah.” (P3)

"Yah bagus mi, sudah nda mau terlalu kasih besar hal yang tidak penting.” (P4)

"Namanya sudah tua, jangan terlalu pusingkan, biasa saja karena kalau banyak lagi yang kita pikir kita sendiriji yang ada rasakan." (P6) 
"Iya tidak ada, begini biasa saja, mau bagaimanakan lagi capek mi juga." (P7)

"Tenang-tenang saja namanya sudah nasib saya pasrah saja, nda tau mau bagaimana lagi itu kasian." (P8)

"Kadang kalau masih ingat yah..kembali lagi terus kami ingatkan lagi, kalau sudah dijenguk atau ditelpon sama keluarganya juga sudah merasa senang." (PT1)

"Baik karena tidak mengulang meski ada beberapa yang mengulang tapi kembali tetap mau kami ingatkan lagi, kalau untuk keluarganya sudah terobati kalau sudah dihubungi." (PT2)

\section{PEMBAHASAN}

\section{Gambaran aplikasi Model Adaptasi Roy dilihat dari tahap input di LRSLU Kendari}

Stimulus fokal pada lansia berupa penyebab masuk di LRSLU. Ketidakberdayaan partisipan menghadapi permasalahan saat usianya lanjut terutama untuk menafkahi dirinya sendiri dan kondisi lingkungan keluarga yang kurang mendukung kehidupan partisipan. Stimulus residual pada lansia berasal luar individu yaitu ketika datang untuk pertama kali ke panti hanya 1 orang yang diantarkan oleh keluarganya, selebihnya dijemput oleh pihak panti. Kedua stimulus yang dialami oleh lansia secara psikologis menimbulkan kesan tidak menyenangkan dan dapat mempengaruhi fase kehidupan selanjutnya.

Tinggal di panti atau LRSLU menjadi pilihan yang mempengaruhi proses adaptasi lansia secara holistik (Alligood, 2014; Padila, 2013). Penelitian sebelumnya yang telah dilakukan oleh Utomo mengungkapkan hal yang sama dengan hasil penelitian ini bahwa terdapat berbagai alasan yang mendasari lansia masuk ke dalam panti dan lansia akan mengalami perubahan sosial yang mengharuskan untuk melakukan penyesuaian diri (Utomo \& Prasetyo, 2012). Kategori penyebab masuk di LRSLU mempengaruhi kehidupan lansia sama seperti hasil penelitian yang dilakukan oleh Adinugraha dengan hasil yang menjabarkan bahwa tahapan dalam Model Adaptasi Roy menggambarkan individu secara holistik dari suatu masalah dan dapat mempengaruhi kehidupannya (Adinugraha, 2014).

\section{Gambaran aplikasi Model Adaptasi Roy dilihat dari tahap control di LRSLU Kendari}

Lansia melewati proses adaptasi pada tahap control dengan mekanisme regulator dan kognator. Pada mekanisme regulator yan ditunjukkan dengan kategori kesehatan lansia didapatkan bahwa secara anatomis dan fisiologis kondisi lansia mengalami perbaikan. Walaupun dijumpai beberapa keluhan, namun lansia dapat mengatasinya dengan mandiri dan rutin memeriksakan kesehatan di poli LRSLU maupun rumah sakit rujukan yang ditunjuk.

Kategori mekanisme koping menjelaskan bagaimana mekanisme kognator sebagai proses emosi, kognitif dan interaksi dengan lingkungannya di panti. Lansia merasakan kesedihan namun dapat memikirkan bahwa fakta yang dialaminya harus dijalani, sehingga lansia memilih untuk bergaul dengan teman sebayanya yang memiliki nasib serupa. Sehingga memunculkan kesadaran bahwa tinggal di LRSLU merupakan pilihan yang tepat dan menyenangkan untuknya saat ini.

Roy menyatakan bahwa model adaptasinya berfokus terhadap hubungan interaksi seseorang dengan orang lain dan terciptanya perilaku adaptif yang membantu kelangsungan hidup bagi seseorang dengan mekanisme koping yang melibatkan fungsi 
anatomi fisiologis dan psikologis dari tubuh dalam mengatasi perubahan lingkungan berperan sebagai seluruh kondisi yang mempengaruhi perkembangan dan perilaku seseorang sebagai sistem adaptasi (Adinugraha, 2014; Padila, 2013).

Hasil penelitian ini serupa dengan penelitian sebelumnya yang menunjukkan bahwa kemandirian juga dipengaruhi oleh perubahan situasi kehidupan seperti kehilangan dukungan keluarga pada hasil penelitian ini, aturan sosial, usia dan penyakit (Nauli et al., 2014). Penelitian ini juga didukung oleh pernyataan penelitian sebelumnya yang telah dilakukan oleh Putri bahwa lansia yang tinggal di panti mengakibatkan perubahan peran lansia dalam menyesuaikan diri, dimana lansia akan mengalami paparan terhadap lingkungan dan teman baru yang mengharuskan lansia beradaptasi secara positif atau negatif (Putri, Fitriana, Ningrum, \& Sulastri, 2015).

\section{Gambaran model Model Adaptasi Roy dilihat dari tahap output di LRSLU Kendari}

Partisipan lansia dalam beradaptasi di LRSLU menunjukkan bahwa setelah melakukan berbagai tindakan untuk mengontrol stimulus yang didapatkannya menghasilkan berbagai respon adaptif terhadap diri maupun lingkungannya. Hal ini menyebabkan perbaikan kondisi psikologis lansia dalam menyesuaikan dirinya dengan kehidupan di LRSLU.

Proses persepsi dan pembelajaran emosi dalam berinteraksi dengan lingkungannya merupakan salah satu proses sistem adaptasi individu dalam menghasilkan konsep diri mengenai keyakinan atau perasaan terhadap suatu hal yang terjadi dalam hidupnya (Padila, 2013). Perilaku individu terhadap stimulus internal dan eksternal yang dialaminya dalam keadaan tertentu akan menghasilkan output berupa respon yang adaptif maupun maladaptif (Purwanti, 2014).

Penelitian ini sesuai dengan penelitian sebelumnya dimana lansia yang dapat menciptakan perasaan-perasaan positif, akan mampu mengatasi masalah adaptasi tersebut, sehingga akan terhindar dari depresi dan menunjukkan respon yang adaptif begitupun sebaliknya (Saputri \& Indrawati, 2011). Penelitian ini juga didukung dengan penelitian sebelumnya yang menyatakan bahwa dukungan sosial berupa perhatian keluarga dan orang di sekitar yang didapatkan lansia berpengaruh nyata positif terhadap kebahagiaan lansia dalam adaptasinya (Nurhidayah \& Agustini, 2012).

Hasil penelitian ini menunjukkan partisipan telah mampu menyesuaikan diri dengan respon terkontrol yang di dapat melalui cara yang beragam namun tetap positif tanpa merugikan orang di sekitarnya. Penelitian ini menunjukkan penyesuaian diri lansia dalam konteks Model Adaptasi Roy bahwa sistem adaptasi manusia melalui beberapa tahap yaitu input, control, dan output dimana dalam kehidupan manusia yang dipengaruhi oleh stimulus internal maupun stimulus eksternal terjadi proses refleksi perilaku individu terhadap proses penyesuaian diri dengan berbagai macam koping yang dilakukan untuk menghasilkan suatu perilaku yang adaptif maupun maladaptif. Pada tahap ini, seseorang akan mendapatkan stimulus fokal, stimulus kontekstual dan stimulus residual yang akan mempengaruhi seseorang dengan berbagai mekanisme koping subsistem regulator, subsistem kognator dan efektor secara fisiologis, konsep diri, fungsi peran dan interdependensi dalam penyesuaian diri yang akan menghasilkan perilaku baik secara internal maupun eksternal dalam 
keadaan tertentu dengan respon yang adaptif maupun maladaptif.

\section{KESIMPULAN DAN SARAN}

Kesimpulan penelitian ini adalah lansia dalam penyesuaian dirinya melalui beberapa tahap yaitu input, control, dan output untuk beradaptasi terhadap lingkungan selama tinggal di LRSLU Kendari dengan perubahan diri dan mekanisme koping yang bervariasi sehingga menghasilkan respon perilaku yang adaptif maupun maladaptif.

Saran peneliti adalah sosialisasi rutin tentang kehidupan adaptasi diri lansia sesuai dengan konteks Model Adaptasi Roy (input, control, dan output) kepada para pekerja sosial khususnya perawat yang bertugas di pelayanan perawatan lansia dan memperhatikan fasilitas yang diberikan agar tak hanya pemenuhan nutrisi saja yang terpenuhi tetapi juga pemenuhan perhatian kepada lansia.

Penelitian ini dapat digunakan sebagai bahan penelitian lanjutan yang mendukung pengembangan ilmu keperawatan gerontik khususnya penyesuaian diri lansia dilihat dari konteks Model Adaptasi Roy. Perawat di ruang perawatan lansia dapat membantu penyesuaian diri lansia dengan berfokus para konsep adaptasi Roy, memahami faktor internal dan eksternal yang dapat mempengaruhi kondisi kesehatan lansia.

\section{DAFTAR PUSTAKA}

Adinugraha, T. S. (2014). Analisis penerapan Model Adaptasi Roy dalam asuhan keperawatan pasien diabetes mellitus, evidence based nursing practice dan inovasi di Rumah Sakit Cipto Mangunkusumo Jakarta. Universitas Indonesia. Depok.

Afiah, W., Yusran, S., \& Sety, L. O. M.
(2018). Faktor risiko antara aktivitas fisik, obesitas dan stres dengan kejadian penyakit hipertensi pada umur 45-55 tahun di wilayah kerja Puskesmas Soropia Kabupaten Konawe tahun 2018. Jurnal Ilmiah Mahasiswa Kesehatan Masyarakat, 3(2), 1-10. doi: 10.37887/jimkesmas.v3i2.3998

Alligood, M. R. (2014). Nursing theorists and their work (8th ed.; D. L. Vogel, Ed.). St. Louis: Elsevier.

Crespo, A. (2019). Panti Sosial Tresna Werdha Minaula berganti nama, ini nama dan tupoksinya. Diperoleh dari https://detiksultra.com/pstw-minaulaberganti-nama-ini-nama-dan-tupoksibarunya

Hadidi, K. (2015). Pengaruh psikoedukasi terhadap pengetahuan, koping, kepatuhan dan tekanan darah pada Lansia dengan hipertensi menggunakan Teori Adaptasi Roy. Universitas Airlangga. Diperoleh dari http://repository.unair.ac.id/45454/

Herawati, N. (2015). Manajemen kasus spesialis keperawatan jiwa pada Lansia dengan harga diri rendah menggunakan pendekatan Model Adaptasi Roy di Ruang Saraswati RSMM Bogor. Universitas Indonesia. Diperoleh dari http://lontar.ui.ac.id/detail?id=204172 11

Indriana, Y., Desiningrum, D. R., \& Kristiana, I. F. (2011). Religiositas, keberadaan pasangan dan kesejahteraan sosial (social well being) pada lansia binaan PMI cabang Semarang. Jurnal Psikologi UNDIP, 
10(2), 184-193. doi: 10.14710/jpu.10.2.184-193.

Isnawati, D., \& Suhariadi, F. (2012). Hubungan antara dukungan sosial dengan penyesuaian diri masa persiapan pensiun pada karyawan PT Pupuk Kaltim. Jurnal Psikologi Industri dan Organisasi, 1(3), 172177.

Jamil, M. (2012). Kepuasan interaksi sosial Lansia dengan tipe kepribadian. Jurnal Keperawatan, 3(2), 171-182.

Nauli, A. F., Yuliatri, E., \& Savita, R. (2014). Hubungan Tingkat Depresi Dengan Tingkat Kemandirian Dalam Aktifitas Sehari-hari Pada Lansia Di Wilayah Kerja Puskesmas Tembilahan Hulu. Jurnal Keperawatan Soedirman, 9(2), 103-110. doi: 10.20884/1.jks.2014.9.2.576

Nurhidayah, S., \& Agustini, R. (2012). Kebahagiaan Lansia ditinjau dari dukungan sosial dan spiritualitas. Jurnal Soul, 5(2), 15-32.

Padila. (2013). Buku ajar keperawatan gerontik. Yogyakarta: Nuha Medika.

Parasari, G. A. T., \& Lestari, M. D. (2015). Hubungan dukungan sosial keluarga dengan tingkat depresi pada Lansia di Kelurahan Sading. Jurnal Psikologi Udayana, 2(1), 68-77. doi: 10.24843/JPU.2015.v02.i01.p07

Prabasari, N. A., Juwita, L., \& Maryuti, I. A. (2017). Pengalaman keluarga dalam merawat Lansia di rumah (studi fenomenologi). Jurnal Ners LENTERA, 5(1), 56-68.

Purwanti, O. S. (2014). Analisis penerapan
Model Adaptasi Roy dalam asuhan keperawatan pasien diabetes melitus, evidence based nursing dan inovasi keperawatan di RSUPN Cipto Mangunkusumo. Universitas Indonesia. Depok.

Putri, S. T., Fitriana, L. A., Ningrum, A., \& Sulastri, A. (2015). Studi komparatif: kualitas hidup Lansia yang tinggal bersama keluarga dan panti. Jurnal Pendidikan Keperawatan Indonesia, 1(1), 1-6. doi: 10.17509/jpki.v1i1.1178

Kementerian Kesehatan Republik Indonesia. (2018). Riset kesehatan dasar 2018. Diperoleh dari http://www.depkes.go.id/resources/do wnload/info-

terkini/materi_rakorpop_2018/Hasil

Riskesdas 2018.pdf

Saputri, M. A. W., \& Indrawati, E. S. (2011). Hubungan antara dukungan sosial dengan depresi pada lanjut usia yang tinggal di Panti Werdha Wening Wardoyo Jawa Tengah. Jurnal Psikologi UNDIP, 9(1), 65-72. doi: 10.14710/jpu.9.1

Utomo, T., \& Prasetyo, E. (2012). Wellbeing pada lansia yang tinggal di panti werdha atas dasar keputusan sendiri. Experientia, 1(1), 57-69. doi: 10.33508/exp.v1i1.53 